\title{
Voltage Stability Analysis of Front-End Speed Controlled Wind Turbine Integrated into Regional Power Grid Based on Bifurcation Theory
}

\author{
Kaide Ren, ${ }^{1}$ Hongwei Li, ${ }^{1}$ Shuaibing Li ${ }^{D},{ }^{2}$ and Haiying Dong ${ }^{1,2}$ \\ ${ }^{1}$ School of Automation and Electrical Engineering, Lanzhou Jiaotong University, Lanzhou 730070, China \\ ${ }^{2}$ School of New Energy and Power Engineering, Lanzhou Jiaotong University, Lanzhou 730070, China \\ Correspondence should be addressed to Shuaibing Li; lishuaibing1105@163.com
}

Received 12 August 2020; Revised 1 September 2020; Accepted 14 September 2020; Published 7 October 2020

Academic Editor: Qiang Chen

Copyright (c) 2020 Kaide Ren et al. This is an open access article distributed under the Creative Commons Attribution License, which permits unrestricted use, distribution, and reproduction in any medium, provided the original work is properly cited.

\begin{abstract}
Since wind power has characteristics such as intermittent and fluctuation, the integration of large-scale wind turbines into the power grid will bring a great impact on the voltage stability of the system. In this paper, the influence of the front-end speed controlled wind turbine (FSCWT) on the system voltage stability is studied. An actual model of the wind turbines, including the FSCWTs, connected to a regional power grid in Zhangye, Gansu Province, is established. Firstly, differential-algebraic equations (DAEs) describing the dynamic characteristics of the wind turbine are given and the mathematical model of the system includes FSCWT is established. The continuation method is used to track the balance solution of the DEAs within given parameter intervals. Based on that, the influence of the reactive power variation and wind speed fluctuation on the stability of system voltage is analyzed through both the bifurcation theory and the time-domain simulation. Results show that the Hopf bifurcation (HB) and the saddle-node bifurcation (SNB) are inherited for the system, indicating that such bifurcations are the essence of nonlinear dynamics that lead to voltage instability. The greater the disturbance of the bifurcation parameter $Q_{1}$, the shorter the time of voltage collapse and the smaller the stable operation area of the system. With the increase of wind speed, the amplitude of system voltage will increase slightly, but the HB point will appear in advance, which is more likely to lead to voltage instability and further reduce the stable operation area of system voltage.
\end{abstract}

\section{Introduction}

With the rapid development of wind power generation technology, wind energy has become increasingly utilized. As an important part of the power system, the new installed capacity and the total installed capacity of the wind turbine are increasing year by year $[1,2]$. By the end of 2019, the installed capacity of wind power in China accounts for about $10.5 \%$ of the total capacity of the system [3]; among which, the installed capacity of wind power accounts for almost $25 \%$ of the total installed capacity in typical areas such as Gansu [4]. To make better use of wind power resources and improve economic benefits, wind power systems at home and abroad are increasingly developing in the direction of large capacity, ultra-high voltage, and long-distance transmission, which greatly increases the difficulty of maintaining the system voltage stability. The integration of wind turbines introduces the fluctuation and indirectness of wind speed into the power system, which will inevitably impact on the voltage stability of the integrated system $[5,6]$. Besides, the voltage of the system will be disturbed by the reactive power fluctuation caused by wind speed variation. Research shows that in the modern power system, voltage stability accident is more sudden than frequency stability and synchronous operation stability [7].

The new energy power system with wind turbines is essentially a nonlinear system $[8,9]$, in which the gridconnected voltage stability of wind turbines will be affected by many factors, such as the interference of natural wind speed and reactive power changes on wind turbines. The change of voltage stability state of wind turbines connected to the regional power grid is essentially the process of the 
whole system from a stable state to the bifurcation. The set of different bifurcation points forms a bifurcation hypersurface. Based on this, G. Aronovich and other scholars introduced the bifurcation theory into the field of power system voltage stability analysis, which has become a powerful tool for studying the structural stability of dynamic systems [10].

Many scholars at home and abroad have done a lot of research on the voltage stability of conventional wind turbines connected to the regional power grid, and have achieved certain results. In [11], through the dynamic modeling of doubly fed wind turbines and the simulation calculation of the power system including wind farms, the results show that the appropriate wind power access is conducive to the improvement of the voltage level of the regional power grid. When the wind power access capacity is too large, it will lead to the phenomenon of line transmission power crossing and voltage instability. In [12], the stability of the grid-connected voltage of the wind turbine with doubly fed induction generator (DFIG) is studied based on the bifurcation theory, and with the increase of reactive power at load nodes, various bifurcation phenomena will occur in the system, which will lead to voltage collapse. With the increase of wind speed, the system voltage stability margin will be smaller and smaller. In [13], the bifurcation theory is used to analyze the direct-drive permanent magnet synchronous generator (PMSG) incorporated into a three-node simple power system, and the injected active power and reactive power compensation capacity are taken as the bifurcation parameters of the wind power system. The results show that in the absence of reactive power compensation, the system operates at a lower voltage level when the system is effectively compensated by capacitance, and the voltage of each node of the system will be significantly increased. Under the condition of high-power wind power injection, the system voltage will be unstable.

The above research mainly focuses on the analysis of grid-connected voltage stability of the conventional wind turbines connected to the grid with converters. One typical feature of such turbines is that they are difficult to provide reactive power and inertia support in case of reactive power shortage or instability of the system [14], and there are many deficiencies in dealing with grid faults. This is mainly because the converter capacity of the DFIG is too small to protect against grid voltage sag. For the wind turbine with PMSG [15], its ability of dynamic response and reactive power regulation are limited owing to the lack of the gearbox. To sum up, although the bifurcation theory has been applied to the grid-connected voltage stability of conventional wind turbines (i.e., DFIG and PMSG), it has not been involved in the front-end speed controlled wind turbine (FSCWT). Based on this, it is of practical significance to analyze the grid-connected voltage stability of the FSCWT by using the bifurcation theory.

In contrast, the FSCWT has many advantages, and which solves the above problems. The essential difference of the FSCWT is that it uses a hydraulic torque converter named WinDrive to regulate the speed of the generator at the frontend of the turbine [16], greatly improving the low voltage ride-through capability of the wind turbine and increasing the advantage of reactive power output [17]. At the same time, the EESG is directly coupled with the power grid, which can provide certain transient support for the system in case of failure or instability of the access system. Therefore, this paper proposes to use the bifurcation theory to study the voltage stability of the regional power grid integrated with FSCWTs.

The rest of this paper is organized as follows: Section 2 listed the structural equation of the power system and introduces different bifurcations, the dynamic differential equations of the system integrated with FSCWTs are modeled in Section 3, operation characteristics and dynamic equivalent modeling of the wind farm are given in Section 4, and voltage stability analysis of FSCWT connected to the regional power grid is simulated in Section 5. Conclusions are finally drawn in Section 6.

\section{Differential-Algebraic Equation of the Power System}

Generally, the stability of the power system can be described by the differential-algebraic equation (DAE), which consists of $n$-dimensional differential equations and $m$-dimensional algebraic equations. Assumed that the two sets of equations are smooth throughout the analysis, the power system can be described using the following equations [18]:

$$
\left\{\begin{array}{l}
\dot{x}=f(x, y, \mu), \\
0=g(x, y, \mu)
\end{array}\right.
$$

where $x$ is an $n$-dimensional differential state variable, $x \in R^{n}$; $y$ is an $m$-dimensional algebraic state variable, $y \in R^{m} ; \mu$ is a $k$-dimensional variable and also a bifurcation parameter in structural stability analysis, $\mu \in R^{k}(k>1$ and $k \in Z), f$ is a differential equation describing the dynamic components of the system, and $g$ is the balanced equation of each node.

All solutions belong to $\left(x_{0}, y_{0}, \mu_{0}\right)$ satisfying that the following equations can be taken as the equilibrium points of the system:

$$
\left\{\begin{array}{l}
f\left(x_{0}, y_{0}, \mu_{0}\right)=0 \\
g\left(x_{0}, y_{0}, \mu_{0}\right)=0
\end{array}\right.
$$

Consequently, equilibrium solutions can be expressed as $M=\{(x, y, \mu) / f(x, y, \mu)=0, g(x, y, \mu)=0\}$.

It can be seen that the greatest advantage of a general power system is to describe the dynamic behavior of the system with DAEs. To study the dynamic stability of the power system shown in (1), the differential transformation of the system at the equilibrium point $\left(x_{0}, y_{0}, \mu_{0}\right)$ can be obtained as

$$
\left\{\begin{array}{l}
\frac{\mathrm{d} \mathbf{x}}{\mathrm{d} t}=D_{x} f\left(x_{0}, y_{0}\right) \cdot \mathrm{d} \mathbf{x}+D_{y} f\left(x_{0}, y_{0}\right) \cdot \mathrm{d} \mathbf{y}, \\
0=D_{x} f\left(x_{0}, y_{0}\right) \cdot \mathrm{d} \mathbf{x}+D_{y} f\left(x_{0}, y_{0}\right) \cdot \mathrm{d} \mathbf{y} .
\end{array}\right.
$$

The differential-algebraic equation describing the dynamic characteristics of the system can be replaced by equation (3): 


$$
\begin{aligned}
\frac{\mathrm{d} \mathbf{x}}{\mathrm{d} t}= & \left\{D_{x} f\left(x_{0}, y_{0}\right)-D_{y} f\left(x_{0}, y_{0}\right)\left[D_{y} g\left(x_{0}, y_{0}\right)\right]^{-1}\right. \\
& \left.\times D_{x} g(x 0, y 0)\right\} \cdot \mathrm{d} \mathbf{x},
\end{aligned}
$$

where $\mathbf{A}=D_{x} f\left(x_{0}, y_{0}\right), \mathbf{B}=D_{y} f\left(x_{0}, y_{0}\right), \mathbf{C}=D_{x} f\left(x_{0}, y_{0}\right)$, and $\mathbf{D}=D_{y} f\left(x_{0}, y_{0}\right)$.

Which can be simplified as

$$
\dot{x}=\left(\mathrm{A}-\mathrm{BD}^{-1} \mathbf{C}\right) \mathbf{x} \text {. }
$$

According to the dynamic theory, the dynamic stability of the system can be determined by the reduced Jacobian matrix J:

$$
\mathbf{J}=\left(\mathbf{A}-\mathbf{B D}^{-1} \mathbf{C}\right)
$$

For a given power system, when the system parameters change continuously and pass a certain critical value, the system balance point or the number of periodic orbits will inevitably change. At this time, the system will have a bifurcation phenomenon. The corresponding parameter value is called bifurcation value, and the corresponding equilibrium point is called a bifurcation point [19]. Therefore, the instability of the power system is usually attributed to the occurrence of bifurcation points in the system parameter space, which include dynamic and static bifurcation points. The two bifurcation points can be distinguished by the eigenvalues of the Jacobian matrix shown in equation (6).

2.1. Solution of the Static Bifurcation Point. The static bifurcation mainly focuses on the behavior change of the number and stability of the equilibrium points of the system along with the parameter variation. Let the eigenvalue of $\mathrm{J}\left(\mu_{0}\right)$ be $\lambda_{a}(\mu)=\alpha_{a}(\mu)+j \beta_{a}(\mu)$, where $\alpha_{a}(\mu)$ and $\beta_{a}(\mu)$ are real functions of the system control parameter $(a=1,2, \ldots, l)$. According to the dynamic theory, when $\mathrm{J}\left(\mu_{0}\right)$ has zero eigenvalues, the left and the right eigenvectors of the zero eigenvalues can be defined, i.e., $v \in R^{n}$ and $w \in R^{n}$. Therefore, the problem of solving the equilibrium solution for the system can be turned into solving the following equations:

$$
\begin{aligned}
& \text { or } \quad\left\{\begin{array}{l}
F(z, \mu)=0, \\
F_{z}(z, \mu) v=0, \\
F_{\mu}^{T}(z, \mu) v=1,
\end{array}\right. \\
& w^{T} F_{z}(z, \mu)=0, \\
& w^{T}(z, \mu)=1,
\end{aligned}
$$

where $F(z, \mu)=\left[f^{T}(x, y, \mu), g^{T}(x, y, \mu)\right]^{T}$ is the equilibrium equation, while $z=\left[\begin{array}{ll}x^{T} & y^{T}\end{array}\right]^{T}$ stands for the state variable.

Therefore, the saddle-node bifurcation (SNB, static bifurcation point) of the system can be obtained by using the Newton-Raphson method to solve equation (5) [20].

2.2. Solution of the Dynamic Bifurcation Point. During system operation, once the disturbance occurs, the equilibrium state of the system and the number of solutions of the equilibrium equation will change with the variation of the control parameters. For a given control vector $\mu$, suppose a nonhyperbolic equilibrium point $x_{0}$ appears in the equilibrium solutions $(x, y, \mu)$ with $\mu=\mu_{0}$ and $x_{0}$ satisfies (1), and it is located on the surface of the equilibrium solution $M$. If a pair of conjugate complex roots with zero real parts appears on the reduced Jacobian matrix $\mathbf{J}$ in equation (6), it is considered that the structural stability of the system changes, resulting in dynamic bifurcation, in which the main dynamic bifurcation point is the Hopf bifurcation [21].

In conclusion, the change of eigenvalues corresponding to the dynamic and static bifurcation points is clearly described in Figure 1.

\section{Dynamic Modeling of the FSCWT}

3.1. Operation Principle of the FSCWT. The FSCWT adopts the transmission form of low-speed ratio gearbox + hydraulic torque converter speed control + brushless electric excitation synchronous generator, and its structure is shown in Figure 2. The biggest advantage of the wind turbine is that the hydraulic torque converter WinDrive is used to realize the stepless speed regulation. In case of a sudden change of wind speed, the hydraulic torque converter WinDrive can withstand such shock and can convert the varied wind speed into the constant input speed of EESG, thereby, to realize the purpose of variable speed input and constant speed output.

To analyze the dynamic characteristics of the wind turbine drive chain system, it is usually equivalent to a multimass model composed of spring and damping. This equivalent method is also applied for the FSCWT. In the structure diagram of the drive chain provided in Figure 3, the characteristics of the rotor speed and the low-speed shaft can be described in the following form [22]:

$$
\mathbf{J}_{R} \frac{\mathrm{d} \omega_{R}}{\mathrm{~d} t}=T_{R}-T_{j}-D_{1} \omega_{R}
$$

while the rotor torque $T_{R}$ can be described as [23]

$$
T_{R}=\frac{P_{1}}{\omega_{R}}=\frac{C_{p}(\lambda, \beta) S V^{3} \rho}{2 \omega_{R}} .
$$

In Figure 3, the torque of the wind wheel and the planetary frame satisfies

$$
\left\{\begin{array}{l}
T_{R} \dot{\omega}_{R}=T_{j} \dot{\omega}_{j}, \\
\omega_{j}=\omega_{R} i_{R j} .
\end{array}\right.
$$

For the torque converter, the dynamic balance equation between the pump wheel and the turbine wheel is

$$
\begin{aligned}
& \left\{\begin{array}{l}
J_{t} \dot{\omega}_{B}=T_{t}-T_{B}-T_{G}, \\
J_{q} \dot{\omega}_{T}=T_{q}-T_{T},
\end{array}\right. \\
& \left\{\begin{array}{l}
T_{T}=\alpha T_{B}, \\
T_{B}=\lambda_{B} \rho_{\text {oil }} \omega_{B}^{2} D^{5} .
\end{array}\right.
\end{aligned}
$$

From the relationship between the turbine speed and the pump wheel speed of the hydraulic torque converter, it can be concluded that [24] 


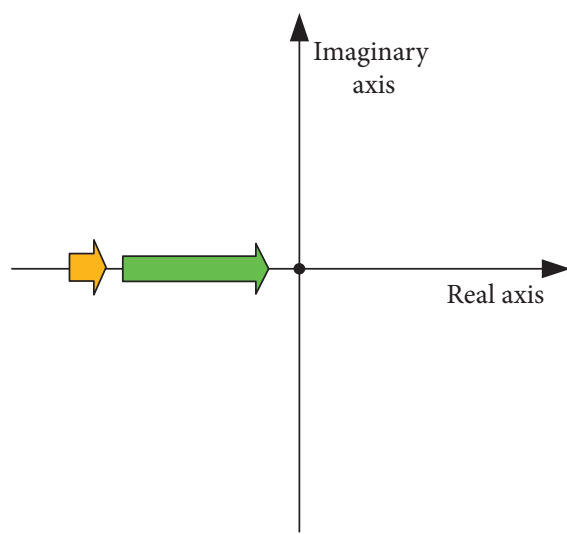

(a)

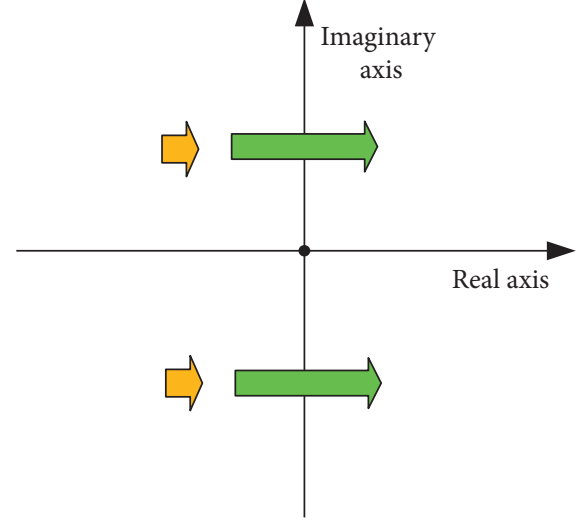

(b)

FIgURE 1: Variation of eigenvalues corresponding to the dynamic and static bifurcation points: (a) static bifurcation; (b) dynamic bifurcation.

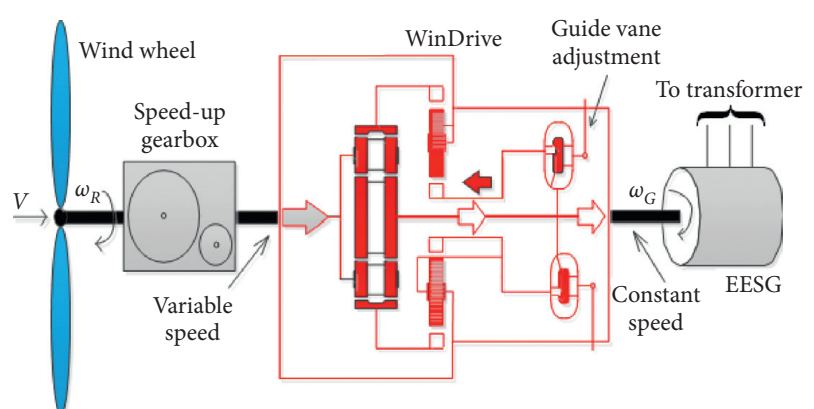

Figure 2: Structure of the FSCWT.

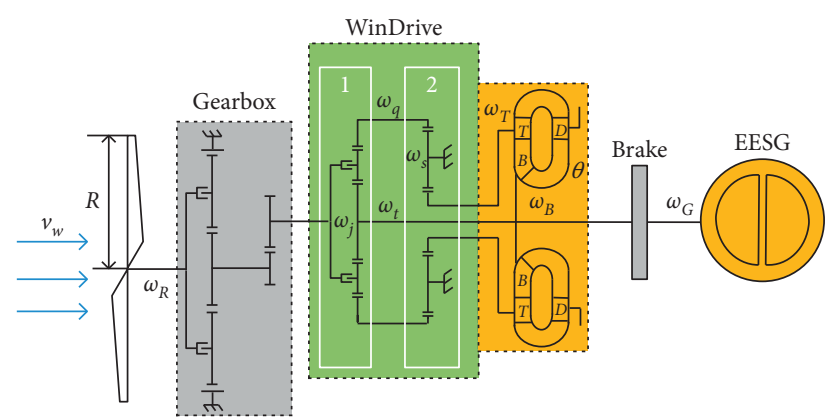

FIgURE 3: Structural chart of drive chain of FSCWT.

$$
\dot{\omega}_{T}=\frac{1+i_{T q}}{1+i_{t q}}\left(\dot{\omega}_{R}-i_{R j} \cdot i_{t q} \cdot \dot{\omega}_{R}\right) .
$$

If the moment of inertia of the high-speed shaft is ignored, the dynamic characteristics of the high-speed shaft and the synchronous generator rotor can be expressed as [25]

$$
J_{G} \frac{\mathrm{d} \omega_{G}}{\mathrm{~d} t}=T_{e}-T_{G}-D_{G} \omega_{G}
$$

3.2. Modeling of EESG. For the EESG, the excitation system can be represented as [26].
In this paper, the fifth-order synchronous generator model is selected for FSCWT for stability analysis [27], which is given as follows:

$$
\left\{\begin{array}{l}
\frac{\mathrm{d} E_{q}^{\prime}}{\mathrm{d} t}=\frac{E_{f d}}{T_{d 0}^{\prime}}-\frac{E_{q}^{\prime}}{T_{d 0}^{\prime}}-\frac{\left(X_{d}-X_{d}^{\prime}\right)}{T_{d 0}} I_{d}, \\
\frac{\mathrm{d} E_{q}^{\prime}}{\mathrm{d} t}=\frac{a E_{f d}}{T_{d 0}^{\prime}}+\left(\frac{1}{T_{d 0}^{\prime}}-\frac{a}{T_{d 0}^{\prime}}\right) E_{q}^{\prime}-\frac{E_{q}^{\prime \prime}}{T_{d 0}^{\prime}}-k I_{d}, \\
\frac{\mathrm{d} E_{d}^{\prime \prime}}{\mathrm{d} t}=-\frac{E_{d}^{\prime \prime}}{T_{d o}^{\prime \prime}}+\frac{X_{q}-X_{d}^{\prime \prime}}{T_{d o}^{\prime \prime}} I_{d}, \\
\dot{E}_{f d}=-\frac{E_{f d}}{\tau_{m}+3 T_{s}}+\frac{K_{\mathrm{PWM}} X_{\mathrm{ad}}}{\left(\tau_{m}+3 T_{s}\right) R_{f}} U_{C},
\end{array}\right.
$$

where $U_{C}$ is the controller output, and $K$ and $c$ are equivalent parameters, and details for each parameter can be found in [28]:

$$
\begin{aligned}
K & =\frac{X_{d}^{\prime}-X_{d}^{\prime \prime}}{T_{\mathrm{do}}^{\prime \prime}}+\frac{c X_{d}^{\prime}-c X_{d}^{\prime \prime}}{T_{\mathrm{do}}^{\prime}}, \\
c & =\frac{X_{d}^{\prime \prime}-X_{1}}{X_{d}^{\prime}-X_{1}} .
\end{aligned}
$$

\section{Operation Characteristics and Dynamic Equivalent Modeling of the Wind Farm}

4.1. Site Location of the Wind Farm for Case Study. In this paper, the Longyuan Pingshan Lake wind farm is selected for the case study. This wind farm is located near Pingshan Lake in Zhangye. The total capacity of this wind farm is $50 \mathrm{MW}$ and includes 25 FSCWTs designed to withstand the sand blow and low-temperature environment in Northwest China [29].

The wind farm is connected to the railway station through a $110 \mathrm{kV}$ transmission line with a line length up to $80 \mathrm{~km}$ and then connected to $330 \mathrm{kV}$ Zhangye substation The topological structure of the regional power system is shown in Figure 4. 


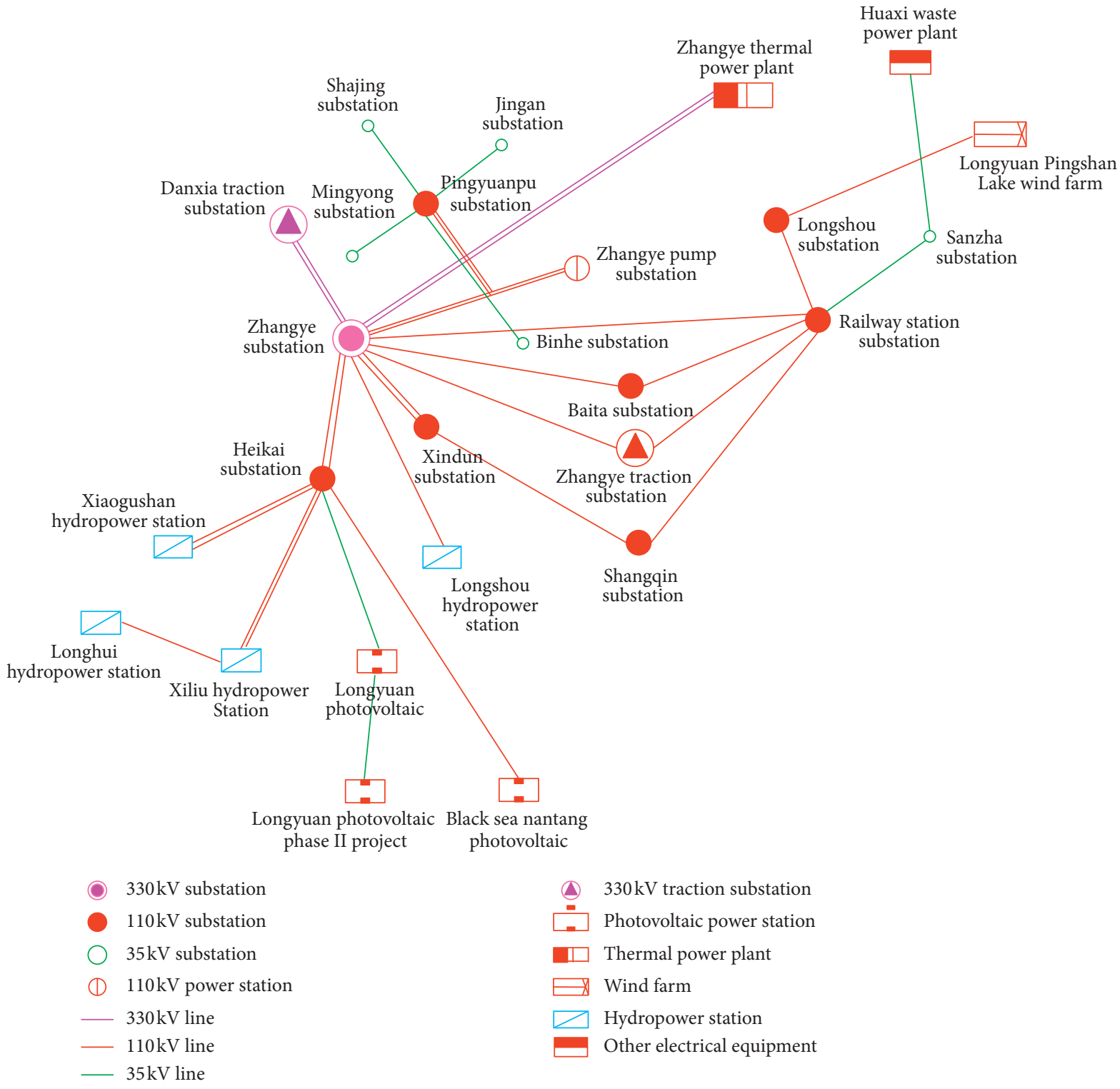

Figure 4: The topological structure of the regional power grid in Zhangye.

4.2. Grid-Connected System Modeling. Figure 5 presents the structure diagram of the FSCWTs integrated into the regional power grid. Each wind turbine is equipped with a step-up transformer ( $35 \mathrm{kV} / 2350 \mathrm{kVA})$ to boost the terminal voltage of the wind turbine from $0.69 \mathrm{kV}$ to $35 \mathrm{kV}$ and then transmitted to the $110 \mathrm{kV}$ station through $35 \mathrm{kV}$ power cables.

As given in Figure 4, the grid structure of the regional power grid is relatively complex and is also composed of many wind turbines. Owing to the large scale of the wind farm, the amount of simulation calculation is too complex, which greatly reduces the efficiency of simulation calculation. This is an important condition for the equivalent treatment of the FSCWT. For such consideration, the region includes the Longyuan Pingshan wind farm, and Zhangye thermal power plant integrated into the $330 \mathrm{kV}$ Zhangye substation is taken as the case. Firstly, the system is simplified through equivalent modeling, the Zhangye thermal power plant is treated as the equivalent power source G1, and the wind farm with FSCWTs is treated as the equivalent power source G2. The equivalent circuit diagram is shown in Figure 6.

Figure 6 is the circuit diagram obtained by equivalent transformation, where node 1 and node 2 stand for the gridconnection point of the thermal power plant and the wind turbine, respectively. Node 3 represents the $330 \mathrm{kV}$ Zhangye substation, while node 4 is the grid-connection point of the wind farm with FSCWT. $E_{1}^{\prime}$ and $S_{1}^{\prime}$ represent the equivalent potential and capacity of the power source G1, respectively. Accordingly, $E_{2}^{\prime}$ and $S_{2}^{\prime}$ represent the equivalent potential and capacity of the wind farm, while $P_{L}$ and $Q_{L}$ stand for the load active power and reactive power of the equivalent system. The voltage and the corresponding phase angle of the wind turbine connected to the system are denoted as $u$ and $\theta$, respectively. Similarly, the voltage and phase angle of the equivalent power source G1 are treated as $u_{1}$ and $\theta_{1}$. The 


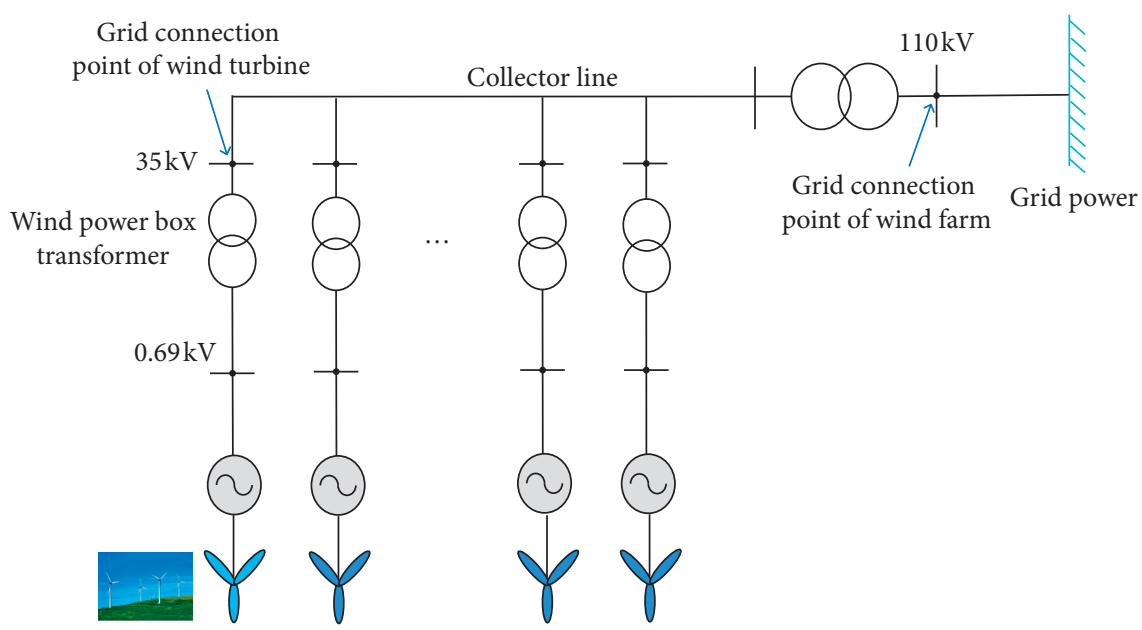

FIGURE 5: Structure diagram of the FSCWT grid-connected system.

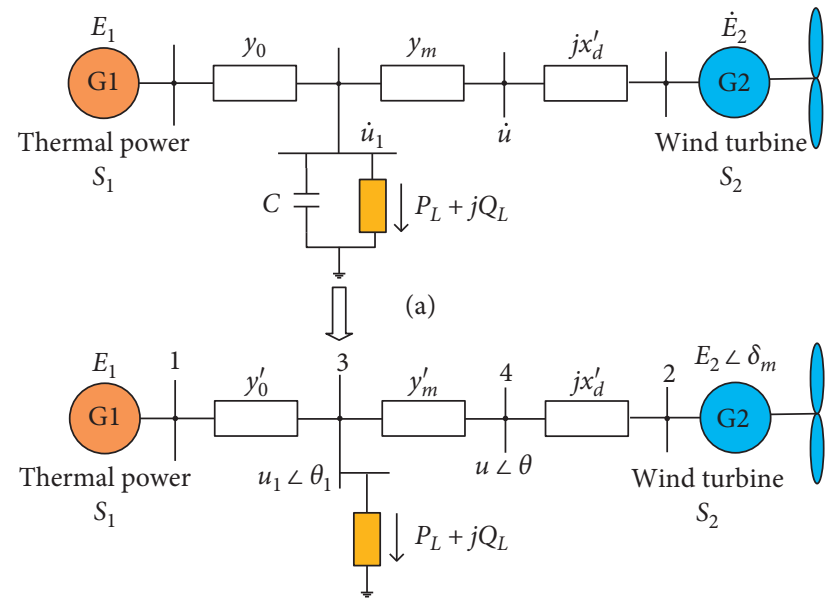

(b)

FIgURE 6: Equivalent circuit diagram.

equivalent admittance between nodes 1 and node 3 is denoted as $y_{0}^{\prime}$, while that between node 3 and node 4 is taken as $y_{m}^{\prime}$.

To approach the actual situation, the IEEE first benchmark model for the grid-connected equivalent generator G2 composed of the FSCWT [30]:

$$
\left\{\begin{array}{l}
\dot{\delta}_{m}=\omega, \\
M \dot{\omega}=T_{m}+u \frac{E_{d}^{\prime} \cos \left(\theta-\delta_{m}\right)+E_{q}^{\prime} \sin \left(\theta-\delta_{m}\right)}{x_{d}^{\prime}}-D_{m} \omega \\
T_{d 0}^{\prime} E_{d}^{\prime}=-\frac{x_{d} E_{q}^{\prime}}{x_{d}^{\prime}}+\frac{\left(x_{d}-x_{d}^{\prime}\right) u \cos \left(\theta-\delta_{m}\right)}{x_{d}^{\prime}}+E_{f d} \\
T_{q 0}^{\prime} E_{d}^{\prime}=-\frac{x_{q} E_{d}^{\prime}}{x_{d}^{\prime}}+\frac{\left(x_{q}-x_{d}^{\prime}\right) u \sin \left(\theta-\delta_{m}\right)}{x_{d}^{\prime}} \\
T_{A} \dot{E}_{f d}=-K_{E}+E_{f d}+K_{A}\left(V_{\mathrm{ref}}-u\right) .
\end{array}\right.
$$

The network algebra equation including the FSCWT is listed as follows:

$$
\left\{\begin{array}{l}
\frac{u E_{q}^{\prime}}{x_{d}^{\prime}} \sin \left(\delta_{m}-\theta\right)=-u_{1} u y_{m} \sin \left(\theta_{1}-\theta\right)-u^{2} y_{m} \sin \left(\theta_{1}-\theta\right), \\
\frac{u E_{q}^{\prime}}{x_{d}^{\prime}} \cos \left(\delta_{m}-\theta\right)=\frac{u^{2}}{x_{d}^{\prime}}-u_{1} u y_{m} \cos \left(\theta_{1}-\theta\right)+u^{2} y_{m} \cos \left(\theta_{1}-\theta\right) .
\end{array}\right.
$$

The power provided by the network to the load side of the grid-connected system is

$$
\left\{\begin{array}{l}
P=-E_{0}^{\prime} u y_{0}^{\prime} \sin \left(\theta+\theta_{1}\right)-E_{m} u y_{m} \sin \left(\theta-\delta_{m}+\theta_{1}\right) \\
+\left(y_{0}^{\prime} \sin \theta_{1}+y_{m} \sin \theta\right) u^{2}, \\
Q=E_{0}^{\prime} u y_{0}^{\prime} \cos \left(\theta+\theta_{1}\right)-E_{m} u y_{m} \cos \left(\theta-\delta_{m}+\theta_{1}\right) \\
-\left(y_{0}^{\prime} \cos \theta_{1}+y_{m} \sin \theta\right) u^{2} .
\end{array}\right.
$$

Here, the dynamic load model is composed of asynchronous motor and constant PQ power. Once denote the 
active load as the function of node voltage change rate with time and frequency $P_{l i}=P_{l i}\left(u_{i}, \mathrm{~d} u_{i} / \mathrm{d} t, \mathrm{~d} \delta / \mathrm{d} t\right)$, while the reactive load is expressed as a function of node voltage and frequency $Q_{l i}=Q_{l i}\left(u_{i}, \mathrm{~d} \delta / \mathrm{d} t\right)$, it can be concluded that

$$
\left\{\begin{array}{l}
P=P_{0}+P_{1}+K_{1} \dot{\theta}+K_{2}\left(u_{2}-T \dot{u}\right), \\
Q=Q_{0}+Q_{1}+K_{3} \dot{\theta}+K_{4} u+K_{5} u^{2} .
\end{array}\right.
$$

Therefore, according to equations (16) (19), the state equation describing the dynamic performance of the system can be summarized as

$$
\left\{\begin{array}{l}
\dot{\delta}_{m}=\omega, \\
M \dot{\omega}=T_{m}+u \frac{E_{d}^{\prime} \cos \left(\theta-\delta_{m}\right)+E_{q}^{\prime} \sin \left(\theta-\delta_{m}\right)}{x_{\mathrm{d}}^{\prime}}-D_{m} \omega, \\
T_{d 0} E_{q}^{\prime}=-\frac{x_{d} E_{q}^{\prime}}{x_{d}^{\prime}}+\frac{\left(x_{d}-x_{d}^{\prime}\right) u \cos \left(\theta-\delta_{m}\right)}{x_{d}^{\prime}}+E_{f d}, \\
T_{q 0} E_{d}^{\prime}=-\frac{x_{q} E_{d}^{\prime}}{x_{d}^{c}}+\frac{\left(x_{q}-x_{d}^{\prime}\right) u \sin \left(\theta-\delta_{m}\right)}{x_{d}^{\prime}}, \\
T_{A} E_{f d}=-K_{E}+E_{\mathrm{fd}}+K_{A}\left(V_{\mathrm{ref}}-u\right), \\
K_{3} \dot{\theta}=-K_{4} u-K_{5} u^{2}+Q_{0}-Q_{0}-Q_{1}, \\
T K_{3} K_{2} \dot{u}=K_{1} K_{5} u^{2}+\left(K_{1} K_{4}-K_{3} K_{2}\right) u+K_{1}\left(Q_{0}-Q+Q_{1}\right)-K_{3}\left(P_{0}-P+P_{1}\right)
\end{array} .\right.
$$

By solving the state differential equations of the system and selecting the control parameters that affect the voltage stability of the system, the stability of the grid-connected voltage is simulated in detail based on the bifurcation method.

The values of the parameters for the equivalent system and load model are provided in Table 1.

\section{Bifurcation Analysis of FSCWT Connected to the Regional Power Grid}

5.1. Influence of Reactive Load Variation on Voltage Stability. The new energy power system with FSCWTs is a typical dynamic nonlinear system. The change of its voltage stability is essentially a process from a stable state to a bifurcation or collapse.

For the grid-connected system, the reactive load power $Q_{1}$ is selected as the bifurcation parameter of the grid side, assuming that the bifurcation parameter $Q_{1}=2.1408$, while the wind speed $V=10 \mathrm{~m} / \mathrm{s}$, and the active power of the load $P_{1}=0$. Therefore, the initial equilibrium point of the system can be obtained using the Newton-Raphson method by solving (20), which is $x=\left(\delta_{m}, \omega, E_{d}^{\prime}, E_{q}^{\prime}, E_{f d}, \theta, u\right)=(2.947,0$, $-0.463,0.26,3.11,0.118,0.97)$. According to the simulation, the curve of voltage $u$ varying with the control parameter $Q_{1}$ at the connection point is shown in Figure 7.
As given in Figure 7, two bifurcation points can be found on the system's equilibrium solution. One is a Hopf bifurcation point, marked as $H_{1}$, and another marked as LP is a saddle-node bifurcation point. The solid blue line indicates that the system is in a stable state, while the dotted red line means the system is in an unstable state. Therefore, this article mainly focuses on the upper half of the $Q_{1}-u$ curve, namely, the area with yellow-shadow in Figure 7.

Further numerical analysis indicates that the first Lyapunov coefficient is negative at $H_{1}$, which means the system is operating in a stable state. The state parameters corresponding to the bifurcation points $H_{1}$ and LP are shown in Table 2.

Once a disturbance occurs and acts on $H_{1}$ on the $Q_{1}-u$ curve, the changes of the $\delta-u$ phase locus plot and the $u-t$ voltage curve can be depicted in Figures 8 and 9. It can be seen from Figure 8 that a limit cycle appears on the system phase locus plot, and the corresponding phenomenon is that the voltage $u$ oscillates with the increase of time $t$, as is shown in Figure 9. Besides, it is also clear from Figure 8 that there is uncertainty phenomenon, namely, the chaos. Based on the above analysis, it can be concluded that the occurrence of a limit cycle will inevitably lead to the Hopf bifurcation.

According to Figure 7 and Table 2, when the system operates at the point $H_{1}$, the corresponding reactive power $Q_{1}$ is 1.294855 p.u., and before this, the system is stable. 
TABle 1: Parameter of the equivalent system and load model.

\begin{tabular}{lc}
\hline Parameter & Value \\
\hline$T_{m}$ & 1.0 \\
$M$ & 0.0637 \\
$y_{0}$ & 20.0 \\
$x_{q}$ & 0.85 \\
$T_{q 0}^{\prime}$ & 0.25 \\
$x_{q}^{\prime}$ & 0.1 \\
$T_{A}$ & 0.2 \\
$K_{1}$ & 0.4 \\
$K_{2}$ & 0.3 \\
$K_{5}$ & 2.1 \\
$P_{0}$ & 0.6 \\
$D_{m}$ & 0.05 \\
$y_{m}$ & 5.0 \\
$x_{d}$ & 0.90 \\
$T_{d 0}^{\prime}$ & 8 \\
$x_{d}^{\prime}$ & 0.1 \\
$u_{\text {ref }}$ & 1 \\
$K_{E}$ & 1.0 \\
$K_{3}$ & -0.03 \\
$K_{4}$ & -2.8 \\
$T$ & 8.5 \\
$Q_{0}$ & 1.3 \\
\hline
\end{tabular}

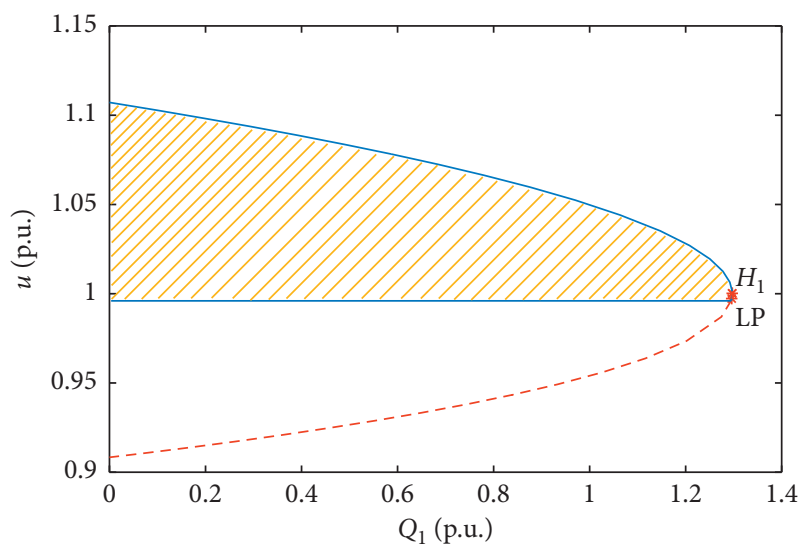

FIgURE 7: $Q_{1}-u$ curve simulation diagram.

TABLE 2: The parameter value of each bifurcation point (in p.u.).

\begin{tabular}{lcc}
\hline \multirow{2}{*}{ Parameter } & \multicolumn{2}{c}{ Bifurcation point } \\
& $H_{1}$ & LP \\
\hline$\delta_{m}$ & 3.234323 & 3.221205 \\
$\omega$ & 0 & 0 \\
$E_{d}^{\prime}$ & -0.891554 & -0.887648 \\
$E_{q}^{\prime}$ & 0.049883 & 0.049893 \\
$E_{f d}$ & 0.003010 & 0.000133 \\
$\theta$ & 0.036403 & 0.023048 \\
$u$ & 1.004215 & 1.000187 \\
$Q_{1}$ & 1.294855 & 1.296925 \\
\hline
\end{tabular}

However, once the system has interfered with a small interference, i.e., $Q_{1}$ suddenly increases from 1.294855 p.u. to 1.39 p.u., or 1.294855 p.u. to 1.49 p.u., or from 1.294855 p.u. to 1.59 p.u., the corresponding simulation results in timedomain are given in Figure 10.
It can be seen from Figure 10 that when the system is subject to small interference $\left(Q_{1}=1.39\right)$, after a short period of stable operation, the bus voltage at the load side will lose stability and eventually lead to voltage collapse at $t=0.57 \mathrm{~s}$. If the value of $Q_{1}$ is increased to $1.49 \mathrm{p} . \mathrm{u}$. continually, it is clear that the stable operation time of the system will be shortened; at $t=0.24 \mathrm{~s}$, the system voltage will become unstable and step into collapse. In conclusion, the stable operation time will become shorter and shorter as the disturbance of the reactive power $\left(Q_{1}\right)$ increases, or namely, the stable operation area of the system voltage will be gradually reduced as the reactive power increases.

5.2. Voltage Bifurcation Analysis with Variable Wind Speed. During operation, the stability of the regional power system includes FSCWTs is not only related to the reactive power but also affected by the wind speed fluctuation. Assuming the wind speed $V=10 \mathrm{~m} / \mathrm{s}$, the initial equilibrium point of the system is $x=\left(\delta_{m}, \omega, E_{d}^{\prime}, E_{q}^{\prime}, E_{f d}, \theta, u\right)=(3.403,0,-0.467$, $0.392,0.208,0.416,0.708)$. By implementing this case on MATCONT [31], the curve of voltage $u$ changing with wind speed $V$ can be obtained, which is shown in Figure 11.

In Figure 11, there are two Hopf bifurcation points $\left(H_{1}\right.$ and $\left.H_{2}\right)$ and two saddle-node bifurcation points ( $\mathrm{LP}_{1}$ and $\mathrm{LP}_{2}$ ) on the $u-V$ curve. The corresponding state parameters of each bifurcation point are given in Table 3 .

In actuality, the cut-out wind speed of the FSCWT is designed as $25 \mathrm{~m} / \mathrm{s}$. According to Figure 11 and Table 3, when the system operates to the point $\mathrm{LP}_{1}$, the wind speed has exceeded $25 \mathrm{~m} / \mathrm{s}$ and beyond the limit wind speed of the wind turbine. The operation area beyond the rated wind speed of the wind turbine is marked in red, which is also an unstable operation area. While the remaining area on the left side is a stable operation area although three bifurcation points are available. This is because the occurrence time of both $\mathrm{LP}_{1}$ and $\mathrm{LP}_{2}$ is later than that of the dynamic bifurcation points $H_{1}$ and $H_{2}$.

The above analysis is only limited to the single parameter bifurcation of system voltage. To better reflect the dynamic characteristics of the FSCWT when connected to the grid, the voltage at the connection point $(V)$ and the load reactive power $\left(Q_{1}\right)$ are selected for the two-parameter bifurcation analysis. The two-dimensional $Q_{1}-u$ curve of the system under different wind speed is shown in Figure 12.

From Figure 12, it is clear that the number of bifurcation points on $Q_{1}-u$ curves is different when the wind speed is different.

When the wind speed $V$ reaches to $15 \mathrm{~m} / \mathrm{s}$, there is only one saddle-node bifurcation point $\mathrm{LP}_{3}$ on the $Q_{1}-u$ curve. As the wind speed decreases to $10 \mathrm{~m} / \mathrm{s}$, in addition to a saddle-node bifurcation point $\mathrm{LP}_{2}$, one Hopf bifurcation point $H_{2}$ will occur on the $Q_{1}-u$ curve. As the wind speed continues to decrease to $5 \mathrm{~m} / \mathrm{s}$, no additional bifurcation points will occur except one Hopf bifurcation point $H_{1}$ and one saddle-node bifurcation point $\mathrm{LP}_{1}$, but the location of the bifurcation points will move to the right side of the curve. The results show that the number of equilibrium solutions 


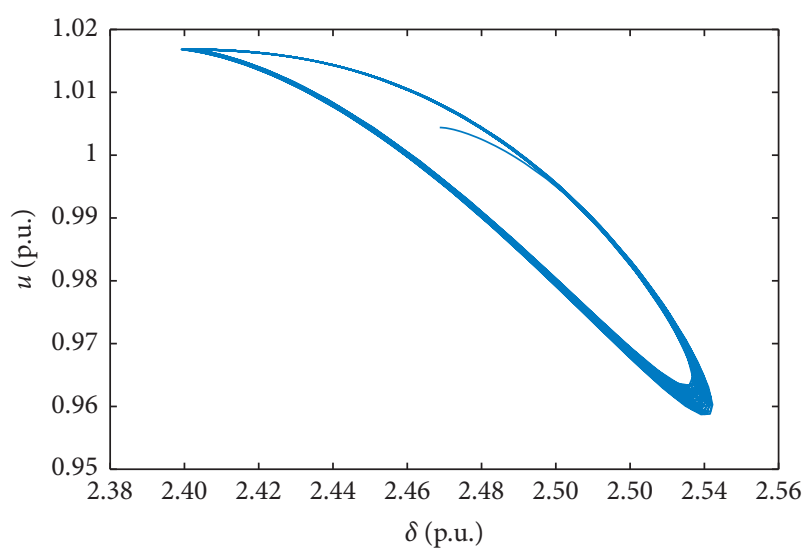

FIGURE 8: $\delta-u_{2}$ phase locus plot.

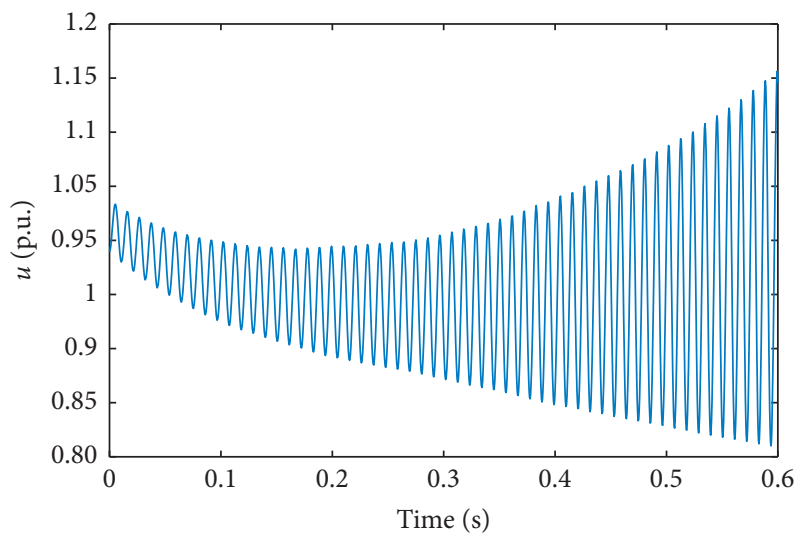

FIGURE 9: $u-t$ curve.

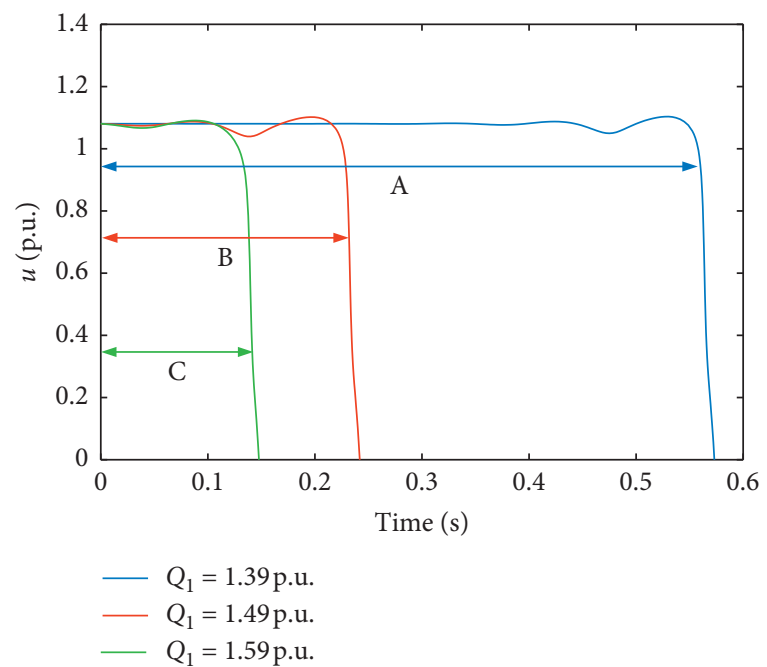

Figure 10: $u-t$ curve of the system after small interference.

on different curves is not only related to the wind speed but also changes with the change of reactive power. With the increase of wind speed, the amplitude of system voltage will rise slightly, which has been marked with a black ellipse in Figure 12. However, the Hopf bifurcation point of the system

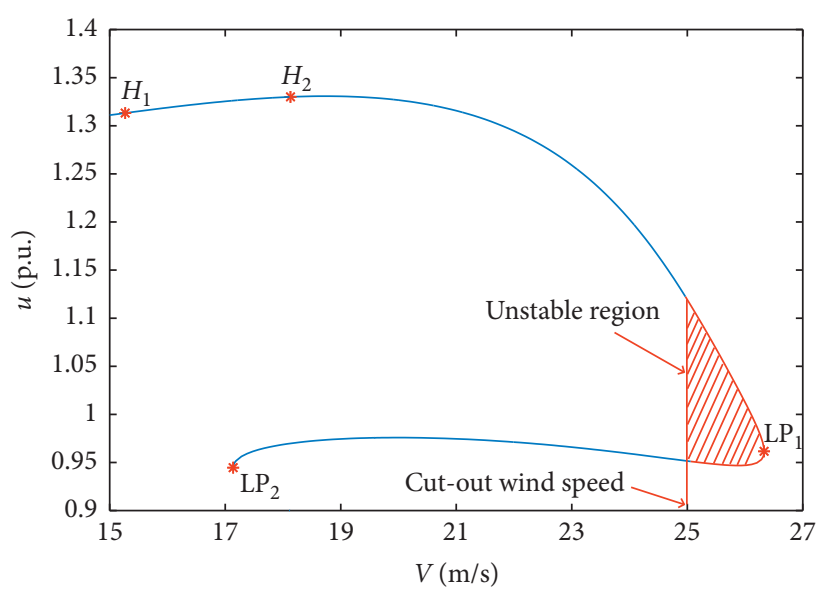

FIgURE 11: $u-V$ simulation diagram.

TABLE 3: The parameter value of each bifurcation point.

\begin{tabular}{lcccc}
\hline \multirow{2}{*}{ Parameter } & \multicolumn{4}{c}{ Bifurcation point } \\
& $H_{1}$ & $H_{2}$ & $\mathrm{LP}_{1}$ & $\mathrm{LP}_{2}$ \\
\hline$\delta_{m}$ & 4.586695 & 4.663054 & 4.622897 & 3.372529 \\
$\omega$ & 0 & 0 & 0 & 0 \\
$E_{d}^{\prime}$ & -0.136046 & -0.186939 & -0.570637 & -0.467516 \\
$E_{q}^{\prime}$ & 1.153463 & 1.162657 & 0.629028 & 0.392306 \\
$E_{f d}$ & -0.223735 & -0.235736 & 0.02399 & 0.208029 \\
$\theta$ & 0.030299 & 0.087054 & 0.646247 & -0.416301 \\
$u$ & 1.313229 & 1.330030 & 0.961642 & 0.708759 \\
$V$ & 15.267681 & 18.129817 & 26.329532 & 23.031749 \\
\hline
\end{tabular}

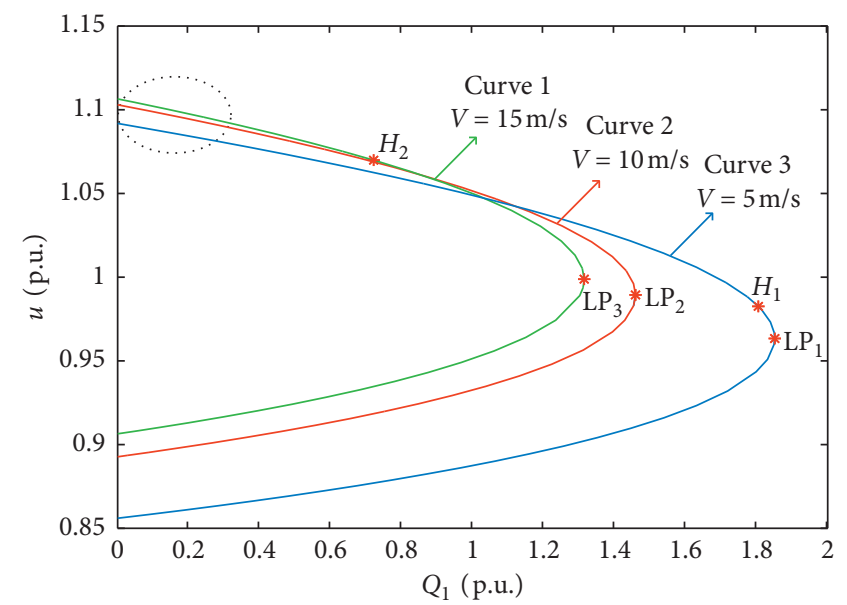

FIgURE 12: $Q_{1}-u$ simulation curve under different wind speeds.

will appear in advance, which is more likely to cause the system voltage instability and further reduce the stable operation area of the system. At the same time, as the wind speed increases gradually, the corresponding reactive power value of the saddle-node bifurcation point in each curve also decreases, which will lead to the reduction of the reactive power capacity of the grid-connected system. 


\section{Conclusions}

In this article, the voltage stability of the FSCWTs connected to the regional power grid is studied. The whole process of the system voltage from instability to collapse is revealed by using bifurcation theory. The critical points of the system bifurcation and voltage collapse are determined under different parameter changes. The analysis and verification are carried out on the MATCONT simulation platform by combining the time-domain simulation method. The following conclusions can be drawn:

(1) The number of bifurcation points on the manifold of the system equilibrium solution is not only related to the fluctuation of wind speed but also related to the disturbance of reactive power of the system.

(2) When the system is subject to small interference, the voltage will fluctuate. The greater the disturbance of the reactive power injected to the grid, the shorter the time of voltage collapse and the smaller the stable operation area of the system. On the other hand, the smaller the operation area of the system, the shorter the stable operation time of the system, and the earlier the system will occur voltage collapse. In short, the shorter the time of system collapse.

(3) From voltage stability analysis using the two-parameter model, it is found that the value of reactive power corresponding to saddle-node bifurcation point LP in each curve will decrease with the gradual increase of wind speed, which will lead to the reduction of the reactive power capacity of the gridconnected system with FSCWTs.

\section{Nomenclature}

$\begin{array}{ll}T_{R}: & \text { Rotor torque } \\ T_{j}: & \text { The output torque of the low-speed shaft } \\ J_{R}: & \text { Moment of inertia of wind wheel } \\ D_{1}: & \text { Damping coefficient of the low-speed shaft } \\ \omega_{R}: & \text { Potor speed } \\ P_{1}: & \text { Power absorbed by the wind turbine } \\ C_{P}: & \text { Area swept by wind turbine } \\ S: & \text { Air density } \\ \rho: & \text { Planetary carrier speed } \\ \omega_{j}: & \text { Moed ratio of the gearbox } \\ i_{R j}: & \text { planetary gear } \\ J_{t}: & \text { Moment of inertia of external gear of the } \\ J_{q}: & \text { planetary gear } \\ \omega_{B}: & \text { Pump wheel speed of the hydraulic torque } \\ \omega_{T}: & \text { converter } \\ T_{t}: & \text { Turbine speed of the hydraulic torque } \\ T_{B}: & \text { converter } \\ T_{G}: & \text { The torque of sun wheel } \\ T_{q}: & \text { The torque of the pump wheel } \\ T_{T}: & \text { Input torque of the generator }\end{array}$

\begin{tabular}{|c|c|}
\hline$\alpha:$ & $\begin{array}{l}\text { Torque ratio of the hydraulic torque } \\
\text { converter }\end{array}$ \\
\hline$\lambda_{B}:$ & Torque coefficient of the pump wheel \\
\hline$\rho_{\text {oil }}:$ & $\begin{array}{l}\text { Oil density of the hydraulic torque } \\
\text { converter }\end{array}$ \\
\hline$D:$ & $\begin{array}{l}\text { The diameter of the circular circle of the } \\
\text { hydraulic torque converter }\end{array}$ \\
\hline$i_{T q}:$ & Speed ratio of the turbine to external gear \\
\hline$i_{t q}:$ & $\begin{array}{l}\text { Speed ratio of the sun wheel to external } \\
\text { gear }\end{array}$ \\
\hline$J_{G}:$ & Moment of inertia of the generator \\
\hline$\omega_{G}:$ & Angular velocity of the generator \\
\hline$T_{e}:$ & Electromagnetic torque of the generator \\
\hline$D_{G}:$ & $\begin{array}{l}\text { Damping coefficient of the high-speed } \\
\text { shaft }\end{array}$ \\
\hline$\delta_{m}:$ & Power angle of the generator \\
\hline$\omega:$ & Angular frequency of the generator \\
\hline$E_{d}^{\prime}, E_{q}^{\prime}:$ & $\begin{array}{l}d, q \text {-axis transient potential of the } \\
\text { generator }\end{array}$ \\
\hline$T_{d 0}^{\prime}, T_{q 0}^{\prime}:$ & $\begin{array}{l}d, q \text {-axis transient time constant of the } \\
\text { generation }\end{array}$ \\
\hline$M, T_{m}, D_{m}:$ & $\begin{array}{l}\text { Inertia, damping and input torque of the } \\
\text { generator }\end{array}$ \\
\hline$x_{d}, x_{q}:$ & $d, q$-axis reactance of the generator \\
\hline$x_{d}^{\prime}, x_{q}^{\prime}:$ & $\begin{array}{l}d, q \text {-axis transient reactance of the } \\
\text { generator }\end{array}$ \\
\hline$u, u_{\mathrm{ref}}:$ & $\begin{array}{l}\text { Terminal voltage and set value of the } \\
\text { generator }\end{array}$ \\
\hline$E_{f d}:$ & Exciter output voltage \\
\hline$T_{A}:$ & Exciter regulation time constant \\
\hline$K_{E}:$ & $\begin{array}{l}\text { Exciter constant related to a self-excited } \\
\text { magnetic field }\end{array}$ \\
\hline$P_{0}, Q_{0}:$ & $\begin{array}{l}\text { Constant power parts of the induction } \\
\text { generator }\end{array}$ \\
\hline$P_{1}, Q_{1}:$ & $\begin{array}{l}\text { Active and reactive power injected into a } \\
\text { wind farm }\end{array}$ \\
\hline$P, Q:$ & $\begin{array}{l}\text { Active and reactive power output from a } \\
\text { wind farm }\end{array}$ \\
\hline $\begin{array}{l}K_{1}, K_{2}, K_{3}, K_{4} \\
K_{5}, T:\end{array}$ & Load parameters. \\
\hline
\end{tabular}

\section{Data Availability}

The data used to support the findings of this study are available from the corresponding author upon request.

\section{Conflicts of Interest}

The authors declare that they have no conflicts of interest.

\section{Acknowledgments}

This work was supported in part by the Tianyou Youth Talent Lift Program of Lanzhou Jiaotong University, in part by the University Innovation Fund Project of Gansu Provincial Department of Education (no. 2020A-036), and in part by the Youth Science Fund Project of Lanzhou Jiaotong University (no. 2019029). 


\section{References}

[1] X. Cai, Z. Qin, and Y. Hou, "Improving wind power utilisation under stormy weather condition by risk-limiting unit commitment," IET Renewable Power Generation, vol. 12, no. 15, pp. 1778-1785, 2018.

[2] L. Wang, R. Yan, and T. Saha, "Voltage regulation challenges with unbalanced PV integration in low voltage distribution systems and the corresponding solution," Applied Energy, vol. 256, 2019.

[3] National Bureau of Statistics, Ranking of Power Data in 2019. Data Sources: National Energy Administration, China International Liaison Bureau, National Bureau of Statistics, Beijing, China, 2019.

[4] Gansu Province has the Fourth Largest Installed Wind Power Capacity in the Country, Data Source: State Grid Gansu Electric Power Company, 2019.

[5] Z. Lorenzo, E. Robert, and G. Spyridon, "Power oscillation damping from VSC-HVDC connected offshore wind power plants," IEEE Transactions on Power Delivery, vol. 31, no. 2, pp. 829-838, 2016.

[6] S. Essallah, A. Bouallegue, and A. Khedher, "Integration of automatic voltage regulator and power system stabilizer: small-signal stability in DFIG-based wind farms," Journal of Modern Power Systems and Clean Energy, vol. 7, no. 5, pp. 1115-1128, 2019.

[7] L. Wang, Research on Fast Evaluation Method of Static Voltage Stability of Power System, Shandong University, Jinan, China, 2007, in Chinese.

[8] N. Jing, A. Chen, Y. Huang et al., "Air-fuel ratio control of spark ignition engines with unknown system dynamics estimator: theory and experiments," IEEE Transactions on Control Systems Technology, 2019.

[9] H. M. Shanechi, N. Pariz, and E. Vaahedi, "General nonlinear modal representation of large scale power systems," IEEE Transactions on Power Systems, vol. 18, no. 3, pp. 1103-1109, 2003.

[10] Z. Peng, G. Hu, and Z. Han, Analysis of Voltage Stability of Power System Based on Bifurcation Theory, China Electric Power Press, Beijing, China, 2005.

[11] Y. Chi, D. Liu, and W. Wang, "Influence of wind power access on the power system," Grid Technology, vol. 2, no. 3, pp. 77-81, 2007.

[12] L. Yang and X. Ma, "Voltage stability analysis of power system with doubly fed wind turbine based on bifurcation theory," Journal of Electrical Technology, vol. 27, no. 9, pp. 1-8, 2012.

[13] Y. Ma, J. Zhang, and X. Zhong, "Study on static voltage stability of power system with wind farm based on bifurcation theory," Power Grid Technology, vol. 2, no. 9, pp. 74-79, 2008.

[14] L. Wang, R. Yan, and F. Bai, "A distributed inter-phase coordination algorithm for voltage control with unbalanced PV integration in LV systems," IEEE Transactions on Sustainable Energy, vol. 11, no. 4, 2020.

[15] Q. Chen, X. Yu, M. Sun, C. Wu, and Z. Fu, "Adaptive repetitive learning control of PMSM servo systems with bounded nonparametric uncertainties: theory and experiments," IEEE Transactions on Industrial Electronics, 2020.

[16] D.-Y. Li, W.-C. Cai, P. Li, S. Xue, Y.-D. Song, and H.-J. Chen, "Dynamic modeling and controller design for a novel frontend speed regulation (FESR) wind turbine," IEEE Transactions on Power Electronics, vol. 33, no. 5, pp. 4073-4087, 2018.

[17] H. Dong, N. Chen, X. Li, and H. Li, "Improved adaptive robust control for low voltage ride-through of front-end speed regulation wind turbine," IEEE Access, vol. 8, no. 1, pp. 55438-55446, 2020.

[18] P. M. Vahdati, A. Kazemi, M. H. Amini, and L. Vanfretti, "Hopf bifurcation control of power system nonlinear dynamics via a dynamic state feedback controller-part I: theory and modeling," IEEE Transactions on Power Systems, vol. 32, no. 4, pp. 3217-3228, 2017.

[19] X. Zhao, X. Zhang, and X. Su, "Study on voltage stability and bifurcation theory of power system," Journal of Electrical Technology, vol. 5, no. 2, pp. 87-95, 2008.

[20] R. J. Avalos, C. A. Canizares, F. Milano, and A. J. Conejo, "Equivalency of continuation and optimization methods to determine saddle-node and limit-induced bifurcations in power systems," IEEE Transactions on Circuits and Systems I: Regular Papers, vol. 56, no. 1, pp. 210-223, 2009.

[21] G. Revel, A. E. Leon, D. M. Alonso, and J. L. Moiola, "Bifurcation analysis on a multimachine power system model," IEEE Transactions on Circuits and Systems I: Regular Papers, vol. 57, no. 4, pp. 937-949, 2010.

[22] H. Li, K. Ren, H. Dong, and S. Li, "On variable-universe fuzzy control for drive chain of front-end speed regulated wind generator," Advances in Fuzzy Systems, vol. 2019, Article ID 2042874, 10 pages, 2019.

[23] S. Wang, Modeling and Simulation of Wind Turbine System of a Wind Turbine, North China Electric Power University, Beijing, China, 2017, in Chinese.

[24] S. Li, Research on Grid-Connected Characteristics of Front-End Speed Controlled Wind Turbine, Lanzhou Jiaotong University, Lanzhou, China, 2014, in Chinese.

[25] H. Yuan, H. Li, and B. Wen, "Nonlinear analysis of synchronous stability of generator rotor," Journal of Northeast University, vol. 22, no. 4, pp. 405-408, 2001.

[26] Q. Xu, Study on the Influence of the IEEEAC5A Excitation System Based on the PSO Algorithm on Power System Stability, Southwest Jiaotong University, Chengdu, China, 2016, in Chinese.

[27] L. Deng, S. Gui, and Z. Wang, "Physical meaning analysis of synchronous generator mathematical model," Northeast Electric Power Technology, vol. 33, no. 12, pp. 5-7, 2012.

[28] H. Dong, S. Li, and L. Cao, "Voltage and reactive power control of front-end speed controlled wind turbine via Ho strategy," TELKOMNIKA Indonesian Journal of Electrical Engineering, vol. 11, no. 8, pp. 4190-4199, 2013.

[29] H. Li, K. Ren, S. Li, and H. Dong, "Adaptive multi-model switching predictive active power control scheme for wind generator system," Energies, vol. 13, no. 6, p. 1329, 2020.

[30] M. Cisneros, C. Hernandez, and R. Morales, "Parameter estimation of a synchronous-generator two-axis model based on the standstill chirp test," IEEE Transactions on Energy Conversion, vol. 28, no. 1, pp. 44-51, 2013.

[31] A. Dhooge and W. Govaerts, "MATCONT: a matlab package for numerical bifurcation analysis of ODEs," ACM Transactions on Mathematical Software, vol. 29, no. 1, pp. 141-164, 2003. 